\title{
3D-Printed Polyester-Based Prototypes for Cosmetic Applications-Future Directions at the Forensic Engineering of Advanced Polymeric Materials
}

\author{
Joanna Rydz ${ }^{1, *(D)}$, Wanda Sikorska ${ }^{1}$, Marta Musioł ${ }^{1}$, Henryk Janeczek ${ }^{1}$, Jakub Włodarczyk ${ }^{1}$, \\ Marlena Misiurska-Marczak ${ }^{2}$, Justyna Lęczycka ${ }^{2}$ and Marek Kowalczuk 1,3,*(D) \\ 1 Centre of Polymer and Carbon Materials, Polish Academy of Sciences, 34, M. Curie-Skłodowska St., \\ 41-800 Zabrze, Poland; wsikorska@cmpw-pan.edu.pl (W.S.); mmusiol@cmpw-pan.edu.pl (M.M.); \\ hjaneczek@cmpw-pan.edu.pl (H.J.); jwlodarczyk@cmpw-pan.edu.pl (J.W.) \\ 2 Laboratorium Kosmetyczne Dr Irena Eris Sp. z o.o., R\&D Department, 12 Armii Krajowej St., \\ 05-500 Piaseczno, Poland; marlena.misiurska-marczak@drirenaeris.com (M.M.-M.); \\ justyna.leczycka@drirenaeris.com (J.Ł.) \\ 3 Faculty of Science and Engineering, University of Wolverhampton, Wulfruna Street, \\ Wolverhampton WV1 1SB, UK \\ * Correspondence: jrydz@cmpw-pan.edu.pl (J.R.); marek.kowalczuk@cmpw-pan.edu.pl (M.K.)
}

Received: 6 March 2019; Accepted: 21 March 2019; Published: 26 March 2019

\begin{abstract}
Knowledge of degradation and impairment phenomena of (bio)degradable polymeric materials under operating conditions, and thus the selection of test procedures and prediction of their behavior designates the scope and capabilities as well as possible limitations of both: the preparation of the final product and its durability. The main novelty and objective of this research was to determine the degradation pathways during testing of polylactide and polylactide/polyhydroxyalkanoate materials made with three-dimensional printing and the development of a new strategy for the comprehensive characterization of such complex systems including behavior during waste disposal. Prototype objects were subjected to tests for damage evolution performed under simulating operating conditions. The reference samples and the tested items were characterized by gel permeation chromatography and differential scanning calorimetry to determine changes in material properties. The studies showed that: polyhydroxyalkanoate component during accelerated aging and degradation in environments rich in microorganisms accelerated the degradation of the material; paraffin accelerates polylactide degradation and slows degradation of polyhydroxyalkanoate-based material; under the influence of an environment rich in enzymes, paraffin contamination accelerates biodegradation; under the influence of natural conditions, paraffin contamination slowed degradation; the processing conditions, in particular the printing orientation of individual parts of the container, influenced the material properties in its various regions, affecting the rate of degradation of individual parts.
\end{abstract}

Keywords: three-dimensional printing; (bio)degradable polyester; prototype container; compostability; biodegradability; weathering test

\section{Introduction}

The use of environmentally friendly polymers for long shelf-life applications as cosmetic packages is a very important trend that should be developed. Materials intended for contact with cosmetic products must perform not only certain functions, but also must meet acceptable standards of safety during use and exhibit chemical and physical stability during storage or transportation. Not only information about cosmetic ingredients, their toxicological profile, traces, or additives that it may contain should be known but also the information on the packaging material, in particular its purity 
and stability is needed [1]. Therefore, it is important to identify the interactions between polymer container and the cosmetic formulation that it contains [2,3]. In this case, the complete replacement of conventional plastics with environmental-friendly packaging is impossible to achieve without recognizing and assessing the possible risks $[4,5]$.

During the preliminary study, polylactide (PLA) limitations have already been observed for applications in cosmetics and household chemistry packaging. Recently, it has been revealed that the process of PLA films degradation occurs in a hydrophobic solvent, such as paraffin, due to the residual moisture content $[2,3,6]$. Despite of some advantageous properties, pure PLA is also stiff and fragile near its glass transition temperature $\left(T_{g}\right.$ in the range from 55 to $65^{\circ} \mathrm{C}$ ), which limits its applications at ambient temperature. In order to expand the range of applications of (bio)degradable polymeric materials containing polylactide, various methods are used to modify PLA properties depending on the intended application, such as mixing with other polymers or additives as natural fillers to obtain blends and composites or copolymerization reaction of lactide with other cyclic esters to obtain (bio)degradable copolymers [7]. An interesting alternative to conventional plastic packaging for cosmetics industry may be use of polyhydroxyalkanoates (PHA)s as modifiers of PLA materials [8-11]. Both PLA and PHA are thermoplastics that are used for traditional extrusion and can also be used in the three-dimensional (3D) printing process, hence (bio)degradable polymers open up new possibilities for 3D technology [12].

3D printing, a manufacturing technology that is able to create 3D objects from a computer-aided design (CAD) file by deposition of multiple layers of material, offers significant advantages over other traditional subtractive manufacturing techniques that allow creating spatial models by removing material using cutting tools. The main advantage is the possibility of produce elements with a designed flexible structure using the number of different materials; therefore, it is important for the final products. 3D printing was originally used for prototyping, but recent progress in this area offer for this technology the possibility to be used on a large scale. So far, the precise 3D printing has found application in the fields of biomedical devices and biocompatible structural components [13]. The next direction is capability to design complexed and well-defined complex structures that are difficult to achieve under currently established manufacturing techniques. Moreover, it is increasingly being used in other areas such as automotive and transportation industry, construction, electronic, and textile sectors as well as consumer goods sector (furniture, suitcases, or safety helmets) [12,13].

The use of (bio)degradable and/or bio-based polyesters increases in areas such as disposable products and short-term and long-term packaging applications, and prediction of the materials applications depend on a full understanding of their behavior and performance throughout their life cycle under the real conditions in which the materials will be used and disposed [14-16]. The packaging of most cosmetics contains hard-to-remove oily substances that may interfere with conventional recycling. It is therefore necessary to look for new materials that could be used as cosmetics packaging and would not create a threat to the environment. Cosmetics packaging from biodegradable polymers can be subjected to the organic recycling process without removing the residue of their content. On the market, we can find applications of biodegradable packaging for cosmetic products-such as lipsticks, powders, bronzers, or eyeshadows - but it is still a small area of application [17-19]. Cosmetics are in contact with the human body (skin, hair, nails) to provide specific functions. Their formulations are therefore complex and to avoid modification of cosmetic properties, the cosmetic composition must be chemically and physically stable during storage and transport. Contaminants can be microbial or chemical and can be caused by improper storage, decomposition reactions, or migration of the products. In general, for packaging from biodegradable and/or compostable polymeric materials, typical end-of-life options (depending on the properties of the polymer) include recycling, monomer recovery (e.g., recovery of lactic acid from PLA and then subsequent use of the recovered monomer), incineration with energy recovery, as well as organic recycling (composting) or landfill disposal [20]. The purpose of composting is the disposal of biodegradable waste and, as a result, to produce a stabilized product that can be used or stored without further treatment. The organic recycling of 
biodegradable polymeric materials enables controlled biological decomposition of these polymers to safe and eco-friendly products for the environment and human life and health [21-24].

So far, there are no available standard testing procedures for biodegradable packages of cosmetic products. Based on the knowledge of the cosmetic formulation and packaging material, as well as on the basis of available standards for packaging of medical, pharmaceutical and food products, particular on (i) Guidelines on stability testing of cosmetics product, Colipa 2004 [25]; (ii) EN 1186, Materials and articles in contact with foodstuffs-Plastics [26]; (iii) EU legislation [27-29] can be developed an evaluation protocol for the assessment of long-term cosmetic packaging from biodegradable polymers. Therefore, the aim of those studies was to elaborate a new strategy for predicting the behavior of such advanced polymer systems based on the comprehensive characterization of degradation pathways.

\section{Materials and Methods}

\subsection{Materials}

The materials used in this study were commercial PLA (Orbi-Tech, Leichlingen, Germany) and PLA/PHA (ColorFabb, Belfeld, The Netherlands) 3D printing filaments. The total carbon content in the PLA and PLA/PHA samples was 49\% and 50\%, respectively (determined by elemental analysis performed by means of a Vario EL III apparatus, Elementar, Langenselbold, Germany). The detailed material characteristic was described in [12].

The following simulants were used for the accelerated aging test: deionized water $(\mathrm{pH}=5.2$, used as reference), liquid paraffin $(99.98 \%$, water content: $0.016 \%$ by Karl Fischer method and the total carbon content: 88\%, from Pharmaceutical Laboratory COEL, Kraków, Poland and anhydrous 99.8\% ethyl alcohol (ethanol, water content: $0.035 \%$ by Karl Fischer method) from POCH SA, Gliwice, Poland were used without further purification.

\subsection{Fabrication of 3D-printed Prototypes of Cosmetic Containers}

PLA and PLA/PHA prototype of cosmetic containers in the form of jars were obtained using fused deposition modeling printer (FLASHFORGE Dreamer dual extrusion 3D printer, FlashForge Corporation, Jinhua, China) with the methodology of 3D structures creation based on bottom-up layer-by-layer manufacturing directly from a CAD model. The printer settings used are shown in Table 1.

Table 1. Printer settings for cosmetic containers fabrication.

\begin{tabular}{cc}
\hline \multicolumn{2}{c}{ Printer Settings } \\
\hline Nozzle diameter $(\mathrm{mm})$ & 0.4 \\
Layer height $(\mathrm{mm})$ & 0.1 \\
Infill pattern & rectilinear \\
Infill density $(\%)$ & 100 \\
Print speed $(\mathrm{mm} / \mathrm{s})$ & 50 \\
Head travel speed $(\mathrm{mm} / \mathrm{s})$ & 100 \\
Nozzle temperature $\left({ }^{\circ} \mathrm{C}\right)$ & 195 \\
Platform temperature $\left({ }^{\circ} \mathrm{C}\right)$ & 65 \\
Printing time $(\mathrm{min})$ & $15-18$ \\
\hline
\end{tabular}

Acetone was used to clean the building platform of any residue after processing the samples. The bottom of the jars and the top of the lids were obtained with flat, XY plane processing build orientation and with raster angle $\left(0^{\circ} / 90^{\circ}\right)$ (cross pattern). The wall of the jar was obtained by printing individual layers, consisting of two concentric, adjoining rings, in the plane XZ one above the other. Cosmetic containers had an average mass of $1.65 \mathrm{~g}$, in particular jars of $0.92 \mathrm{~g}$ and lids of $0.73 \mathrm{~g}$ for PLA material and $1.72 \mathrm{~g}$, in particular jars of $0.92 \mathrm{~g}$ and lids of $0.80 \mathrm{~g}$ for PLA/PHA material. 


\subsection{Modeling and Simulation of Degradation and Damage Phenomena}

\subsubsection{Accelerated Aging Test}

An accelerated shelf life study is based on the Arrhenius model and states that the increasing temperature of $10^{\circ} \mathrm{C}$ doubles the chemical reaction rate [30,31]. The accelerated aging time (AAT) needed to establish equivalence of aging in real time is determined by dividing the desired (or required) shelf life by an accelerated aging factor (AAF). The AAF is calculated using the following equation:

$$
\mathrm{AAF}=Q_{10}{ }^{\left[\left(T_{A A}-T_{R T}\right) / 10\right]}
$$

where $Q_{10}$ is an aging factor for $10^{\circ} \mathrm{C}$ increase or decrease in temperature, $T_{A A}$ is accelerated aging temperature $\left({ }^{\circ} \mathrm{C}\right)$, and $T_{R T}$ is ambient (warehouse) temperature $\left({ }^{\circ} \mathrm{C}\right)$. Using the Arrhenius equation with $Q_{10}$ equal to 2 is a common and conservative way of calculating an aging factor, especially in the case of medical devices. Accordingly, the selected parameters for the experiment were: $T_{A A}=55^{\circ} \mathrm{C}$ (test temperature is generally ranges from $50{ }^{\circ} \mathrm{C}$ to $60^{\circ} \mathrm{C}$, most often $55{ }^{\circ} \mathrm{C}$ ); $T_{R T}=22{ }^{\circ} \mathrm{C}$ (ambient/storage temperature is typical between $22{ }^{\circ} \mathrm{C}$ and $25{ }^{\circ} \mathrm{C} ; 22{ }^{\circ} \mathrm{C}$ results in the shortest duration of the test); $Q_{10}=2$. Relative humidity $R H=5 \%$ is not a factor of the Arrhenius equation, however, the relative humidity should be kept below $20 \%$ so in order not to damage the material. For the accelerated aging test PLA and PLA/PHA cosmetic containers (jars with lids) were dried under vacuum at ambient temperature to a constant mass to eliminate ultimate water content and then were filled with $1 \mathrm{~mL}$ of a cosmetic simulant (deionized water, paraffin, or ethanol) and incubated at $T_{A A}=55^{\circ} \mathrm{C} \pm 1{ }^{\circ} \mathrm{C}$ together with blank test (empty cosmetic container). After a predetermined accelerated aging times $(9,19,37$, 74,111 , and 185 days corresponding to real-time aging 3, 6, 12, 24, 36, and 60 months respectively) the cosmetic containers were opened and separated from the simulants. For the deionized water and ethanol, the samples were washed with deionized water to remove degradation products and dried under vacuum at ambient temperature to a constant mass. For the viscous simulant, paraffin, the samples were drained on a filter paper. The experiments were performed in triplicate.

\subsubsection{Packaging/Cosmetic Formulation Compatibility Test}

Tests with real cosmetic formulations were conducted under two temperature conditions, at ambient temperature $\left(23^{\circ} \mathrm{C} \pm 2{ }^{\circ} \mathrm{C}\right.$, control experiment) and in a heating chamber at $45^{\circ} \mathrm{C}$ (accelerated aging) for a period of 84 days (12 weeks). In the middle of the test, after 42 days (6 weeks, preliminary assessment), and finally after 84 days (12 weeks, final assessment) the stability of the cosmetic formulations and cosmetic containers was checked. Five different cosmetic formulations (oil-in-water emulsions) ranging from the lightest (moisturizing) to heaviest (oily) in an amount of $1.5 \mathrm{~g}$ were selected for the experiment and placed in closed PLA and PLA/PHA cosmetic containers. The experiment was performed in quintuplicate.

\subsubsection{Composting under Laboratory Conditions}

The biodegradation under laboratory conditions was performed using S/N 110315 Micro-Oxymax respirometer (COLUMBUS INSTRUMENTS, Columbus, OH, USA) equipped with a computer as a controller and a device for recording, archiving and presenting data. Micro-Oxymax respirometer performs periodic measurements in a closed system, which means that the air in the measuring chamber is pumped by a gas sensor and returns to the chamber. The system, work in standard conditions, automatically compensates for changes in pressure and temperature [32]. The installed software allows continuous monitoring of the level of carbon dioxide $\left(\mathrm{CO}_{2}\right)$ emission in a closed system. The tested samples and additionally, the $500 \mathrm{~g}$ of thin-layer chromatography analytical grade cellulose as positive control was placed in a glass containers. For control experiment, $500 \mathrm{~g}$ of mature compost without sample was placed in a glass container (blank inoculum). The amount of released $\mathrm{CO}_{2}$ produced from the tested samples (corrected for that derived from the blank inoculum) was monitored 
as a function of time. The cumulative value of $\mathrm{CO}_{2}$ obtained in the test was used to determine the degree of biodegradation of studied materials. The degree of biodegradation $(B)$ was calculated as the ratio of the measured amount of $\mathrm{CO}_{2}$ evolved to the theoretical amount of $\mathrm{CO}_{2}\left(\mathrm{Th}_{\mathrm{CO}_{2}}\right)$ :

$$
B=\left[\left(m_{\mathrm{CO}_{2} \text { test }}-m_{\mathrm{CO}_{2} \text { blank }}\right) / \mathrm{Th}_{\mathrm{CO}_{2}}\right] \times 100 \%
$$

where $m_{\mathrm{CO}_{2} \text { test }}$ and $m_{\mathrm{CO}_{2} \text { blank }}$ are the amount of $\mathrm{CO}_{2}[\mathrm{mg}]$ evolved from tested material and blank inoculum, respectively. The $\mathrm{Th}_{\mathrm{CO}_{2}}$ is calculated based on the total carbon content of the polymer $(\mathrm{TC} \%)$ assuming the total oxidation of the carbon to $\mathrm{CO}_{2}$ according to the equation:

$$
\mathrm{Th}_{\mathrm{CO}_{2}}=(44.0095 / 12.0107) \times\left[\left(m_{s} \times \mathrm{TC} \%\right) / 100\right]
$$

where $m_{s}$ is the amount of sample tested (mg), 44.0095 and 12.0107 molar mass of $\mathrm{CO}_{2}$ and atomic mass of $C$, respectively [33,34].

For the biodegradation test the samples: (i) empty cosmetic containers and (ii) cosmetic containers with a small amount of paraffin $(0.3 \mathrm{~g})$ simulating the packaging with cosmetic contamination, three items of tested cosmetic containers were placed in a glass container containing $500 \mathrm{~g}$ of mature compost (from the Sorting and Composting Plant in Zabrze, Poland) used as a solid bed, a source of nutrients and an inoculum rich in thermophilic microorganisms. Mature compost used cannot be sterilized as its natural flora (bacteria and fungi together) is necessary to carry out a biodegradation test. The compost was sieved, and the obvious plant and other inert materials were removed. The environmental humidity was $43 \%$ for PLA and $42 \%$ for PLA/PHA cosmetic containers and incubated time 12 weeks (84 days, according to USA standard ASTM D 6400 [35]) in the average temperature $58^{\circ} \mathrm{C}$. After incubation the samples were removed, cleaned of compost and analyzed.

\subsubsection{Degradation under Industrial Composting Conditions}

The samples were incubated in cages in BIODEGMA system and in the static composting open-air pile (location: latitude $50^{\circ} 18^{\prime} 30.71^{\prime \prime} \mathrm{N}$ and longitude $18^{\circ} 48^{\prime} 18.52^{\prime \prime} \mathrm{E}$ ) at the Sorting and Composting Plant in Zabrze, Poland as described in [36]. The BIODEGMA composting system features simple, economic and efficient technological solutions for biodegradation of organic waste, including separately collected biogenic and garden waste, sewage sludge, and the organic component of mixed municipal waste. In the BIODEGMA system, the samples were incubated for 21 days (3 weeks) at an average temperature of $60^{\circ} \mathrm{C} \pm 5^{\circ} \mathrm{C}$ with an average $\mathrm{pH}$ of 7.5. In the composting pile, samples were incubated for 21 and 84 days ( 3 and 12 weeks) at an average temperature of $61^{\circ} \mathrm{C} \pm 5{ }^{\circ} \mathrm{C}$ with an average $\mathrm{pH}$ of 6.9. The cages with the materials studied were placed into composting systems at a depth of 0.5 meter below the compost surface. The samples were run in triplicate and the experiments were conducted between July and October 2018.

\subsubsection{Weathering Test}

For degradation under natural weathering conditions the PLA and PLA/PHA cosmetic containers were placed on the testing site at the latitude $50^{\circ} 18^{\prime} 52.68^{\prime \prime} \mathrm{N}$ and longitude $18^{\circ} 46^{\prime} 16.20^{\prime \prime}$ E. Experiments were conducted between September 2016 and August 2017 (12 months), with daily rainfall below $43.8 \mathrm{~mm}$ (http:/ /www.wunderground.com/) The average open-air temperature was $13^{\circ} \mathrm{C}$.

\subsection{Characterization}

The following, most representative, characterization methods were selected [12,37].

\subsubsection{Humidity Analysis}

For humidity analysis the AXIS AGS50 (Gdańsk, Poland) moisture analyzer with the halogen heaters was used. The halogen heaters with a nominal power of $200 \mathrm{~W}$ and $1=118 \mathrm{~mm}$ are connected 
in series. The material humidity was determinate upon the basis of mass loss during drying the sample (thermo-gravimetrical method).

\subsubsection{Gel Permeation Chromatography (GPC) Analysis}

The molar mass and molar-mass dispersity of the samples were determined using gel permeation chromatography conducted in chloroform solution at $35^{\circ} \mathrm{C}$ with an eluent flow rate of $1 \mathrm{~mL} / \mathrm{min}$ using a Viscotek VE 1122 (Malvern, UK) pump with two Mixed C PLgel styragel columns (Agilent, Santa Clara, CA, USA) in series and a Shodex SE 61 RI detector (Showa Denko, Munich, Germany). Polystyrene standards (Calibration Kit S-M-10, Polymer Laboratories) with narrow molar-mass dispersity were used to generate a universal calibration curve. The samples were measured using OmniSEC 5.0 (Viscotek, Malvern, UK) software. The molar mass loss was calculated using the equation:

$$
\% \text { molar mass loss }=\left[\left(M_{w 0}-M_{w x}\right) / M_{w 0}\right] \times 100 \%
$$

where $M_{w 0}$ is the initial mass-average molar mass and $M_{w x}$ is the consecutive or final average molar mass.

\subsubsection{Differential Scanning Calorimetry (DSC)}

Thermal characteristics of the materials were obtained using the TA-DSC Q2000 apparatus (TA Instruments, Newcastle, DE, USA). The instrument was calibrated with high purity indium. The first calorimetric trace (first heating run) of the initial sample in which the thermal history is suppressed was acquired from $-30{ }^{\circ} \mathrm{C}$ to $220^{\circ} \mathrm{C}$ at the heating rate of $20^{\circ} \mathrm{C} / \mathrm{min}$ and of $5{ }^{\circ} \mathrm{C} / \mathrm{min}$, the second and third calorimetric traces (second and third heating run) of the sample was acquired from $-30{ }^{\circ} \mathrm{C}$ to $220^{\circ} \mathrm{C}$ after rapid cooling from $200^{\circ} \mathrm{C}$ at the heating rates of $20^{\circ} \mathrm{C} / \mathrm{min}$ and $5{ }^{\circ} \mathrm{C} / \mathrm{min}$. All of the experiments were performed under a nitrogen atmosphere with the nitrogen flow rate of $50 \mathrm{~mL} / \mathrm{min}$, using aluminum sample pans. The glass transition temperature $\left(T_{g}\right)$ taken as the midpoint of the heat capacity change was obtained from the second calorimetric trace, the cold crystallization temperature $\left(T_{c c}\right)$, the melting temperature $\left(T_{m}\right)$ taken as the peak temperature maximum of the melting endotherm and the enthalpy values $\left(\Delta H_{c c}\right.$ and $\left.\Delta H_{m}\right)$ were obtained from the first calorimetric trace (first heating run) and for the amorphous samples from the second and third calorimetric traces (second heating runs with different heating rates) after rapid cooling from the melt $\left(220^{\circ} \mathrm{C}\right)$.

\section{Results and Discussion}

\subsection{Properties of 3D-Printed Cosmetic Containers}

Previous studies have shown that the processing conditions, in particular the contact time with the 3D printer platform, and smaller specimen's surface contact area lead to an increase in crystalline phase during printing. During hydrolytic degradation, both crystallinity and weaker cohesion between the two printed layers of transverse pattern caused changes during degradation. The build direction and layer orientation proved to be a more important parameter conditioning degradation than the hydrophobicity of the specimens. In general, the direction of 3D printing is an important parameter that should be taken into account when designing 3D printed material applications [12,37], therefore the prototype of cosmetic containers have been carefully examined to determine the differences in the properties of their individual parts - the jar bottom or lid top as well as walls.

In order to evaluate the changes in the thermal properties of the tested samples as a consequence of the thermal history during the processing by 3D printing, DSC analysis was conducted (Table 2). 
Table 2. Selected calorimetric parameters of PLA and PLA/PHA filament and cosmetic container parts. I-heating run and II-heating run (after rapid cooling from $200{ }^{\circ} \mathrm{C}$ at $20^{\circ} \mathrm{C} / \mathrm{min}$ ).

\begin{tabular}{ccccccc}
\hline Variable & $\begin{array}{c}\text { PLA } \\
\text { Filament }\end{array}$ & $\begin{array}{c}\text { PLA Jar } \\
\text { Wall }\end{array}$ & $\begin{array}{c}\text { PLA Jar } \\
\text { Bottom }\end{array}$ & $\begin{array}{c}\text { PLA/PHA } \\
\text { Filament }\end{array}$ & $\begin{array}{c}\text { PLA/PHA } \\
\text { Jar Wall }\end{array}$ & $\begin{array}{c}\text { PLA/PHA } \\
\text { Jar Bottom }\end{array}$ \\
\hline \multicolumn{7}{c}{ I-heating run } \\
\hline$T_{m}\left({ }^{\circ} \mathrm{C}\right)$ & - & 152.0 & 151.2 & $152.2 / 172.8$ & $154.0 / 172.0$ & $151.8 / 171.1$ \\
$\Delta H_{m}(\mathrm{~J} / \mathrm{g})$ & - & 1.88 & 2.45 & 18.50 & 20.94 & 21.0 \\
$T_{c c}\left({ }^{\circ} \mathrm{C}\right)$ & - & 133.2 & 129.3 & 111.9 & 116.2 & 114.1 \\
$\Delta H_{c c}(\mathrm{~J} / \mathrm{g})$ & - & -1.79 & -2.92 & -18.36 & -20.63 & -20.55 \\
\hline \multicolumn{7}{c}{ II-heating run } \\
\hline$T_{g}\left({ }^{\circ} \mathrm{C}\right)$ & 61.8 & 61.9 & 61.1 & $1.7 / 60.5$ & $1.7 / 59.6$ & $2.0 / 59.7$ \\
$\Delta c p\left(\mathrm{~J} / \mathrm{g}^{\circ} \mathrm{C}\right)$ & 0.50 & 0.47 & 0.52 & $0.05 / 0.49$ & $0.06 / 0.46$ & $0.06 / 0.46$ \\
$T_{m}\left({ }^{\circ} \mathrm{C}\right)$ & - & 153.3 & 149.6 & $154.4 / 175.1$ & $153 / 173.3$ & $154.1 / 173.6$ \\
$\Delta H_{m}(\mathrm{~J} / \mathrm{g})$ & - & 0.06 & 0.38 & 0.40 & 0.70 & 0.65 \\
$T_{c c}\left({ }^{\circ} \mathrm{C}\right)$ & - & 140.5 & 138.2 & 134.4 & 142.1 & 142.5 \\
$\Delta H_{c c}(\mathrm{~J} / \mathrm{g})$ & - & -0.08 & -0.32 & -0.36 & -0.68 & -0.62 \\
\hline
\end{tabular}

$T_{g}$ - glass transition temperature, $\Delta c p$-the increment of heat capacity at the glass transition, $T_{m}$-melting temperature, $\Delta H_{m}$-melting enthalpy, $T_{c c}$-maximum of the exothermic peak of the cold crystallization temperature, $\Delta H_{c c}$-cold crystallization enthalpy.

The DSC results of the PLA filament show only a glass transition temperature suggesting that the filament is amorphous. The presence of PHA component in the filament not only plasticizes but also initiate the crystallization of the blend by nucleation as the nucleation agent (Table 2). Likewise during 3D printing, tensile forces acted upon the filament, resulting in a stress-induced crystallization and orientation of the layers of printed elements, and also individual parts of the cosmetic container had a different contact time with the printer platform [2,12]. The jar bottom or lid top had a longer contact time (15-18 $\mathrm{min}$ ) and were subjected to a higher temperature for longer time. The walls, away from the platform, were less influenced by temperature, which affected the thermal properties of these parts. The melting and cold crystallization enthalpies for the PLA jar bottom were higher $\left(\Delta H_{m}=2.45 \mathrm{~J} / \mathrm{g}\right.$ and $\left.\Delta H_{c c}=2.92 \mathrm{~J} / \mathrm{g}\right)$ than for the jar wall $\left(\Delta H_{m}=1.88 \mathrm{~J} / \mathrm{g}\right.$ and $\left.\Delta H_{c c}=1.79 \mathrm{~J} / \mathrm{g}\right)$, which indicates that the processing, especially contact time with printer platform causes an increase in the crystalline phase of these parts of the jar. For the PLA/PHA blend, these effects were slightly lower than in the case of PLA material. After 3D printing of cosmetic containers results show that the material crystallizes during heating. In the second heating run at $20^{\circ} \mathrm{C} / \mathrm{min}$, crystallization and melting effects are low, which indicates slow nucleation and crystallization.

A slower first heating rate of $5{ }^{\circ} \mathrm{C} / \mathrm{min}$ for the PLA/PHA blend (data not shown) allows nucleation and crystal growth in the sample to give a multiple melting endotherm with three $T_{m}$ values $\left(143.8^{\circ} \mathrm{C}\right.$, $152.5^{\circ} \mathrm{C}$ and $173.4^{\circ} \mathrm{C}$ ). Further extension of the crystallization time causes only in a slight decrease in the cold crystallization temperature from $94.1^{\circ} \mathrm{C}$ at $5^{\circ} \mathrm{C} / \mathrm{min}$ to $89.5^{\circ} \mathrm{C}$ at $2.5^{\circ} \mathrm{C} / \mathrm{min}$.

The processing conditions, in particular the printing orientation of individual parts of the container, influenced the material properties, which can then affect the time of use and degradation process of these individual parts, especially their disintegration.

\subsection{Accelerated Aging Test}

Long-term storage is simulated by an accelerated shelf life study. Accelerated aging is an artificial procedure that allows to determine the lifespan or shelf-life of the product at an accelerated pace [29]. According to the standard, it is "storage of samples at an elevated temperature in order to simulate real time aging in a reduced amount of time" [38]. The data obtained in the study are based on conditions simulating the effects of aging of materials. The results of the accelerated aging test of the packaging-product system simulate the requested period up to the expiry date of the product ( 3 months, 6 months, one year, etc.). Accelerated aging data is accepted only if those tests can be repeated in real time and demonstrates the stability of both packaging and product materials over time. This method is widely used in stability tests of pharmaceutical and food packaging [30]. The progress of material aging was estimated by material examination and failure analysis (macroscopic observations 
of the specimens' surfaces), the specimens' molar mass and thermal properties changes during the performed experiments.

A preliminary test of accelerated aging at $55{ }^{\circ} \mathrm{C}$ of prototype PLA packages using cosmetic simulants (paraffin, ethanol, deionized water and blank test) performed over a period of 37 days (real-time aging of one year) have shown that cosmetic containers were deformed from the beginning of experiment. In the case of paraffin and blank test, the concavity of the cosmetic containers was found, in the case of ethanol swelling, and in the case of deionized water-both the concavity and swelling. Deionized water and ethanol evaporated, however ethanol evaporated more slowly, because the swelling cosmetic container kept its tightness. Figure 1 shows photomacrographs of the containers after 19 days of degradation. After this time, the deformation did not change much.

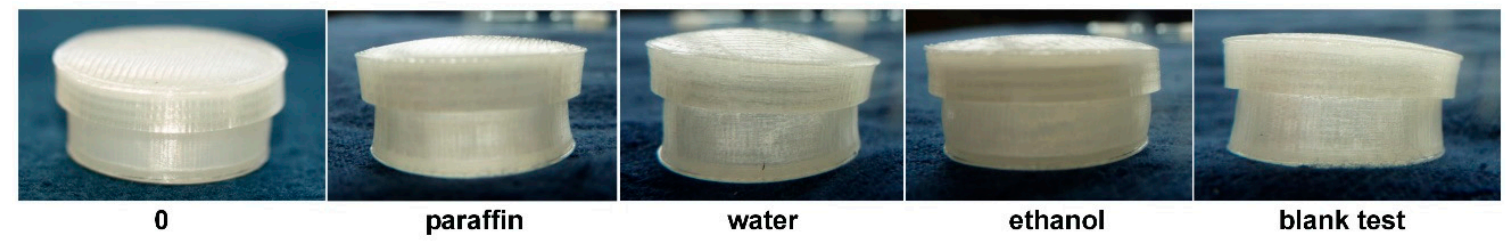

Figure 1. Photomacrographs of PLA cosmetic containers filled with paraffin, ethanol, deionized water, and blank test after 19 days of the accelerated aging test at $55^{\circ} \mathrm{C}$.

Materials from PLA easily deformed at low temperatures due to the relatively low glass transition temperature between $55{ }^{\circ} \mathrm{C}$ and $65{ }^{\circ} \mathrm{C}$ [39]. The PHA component of the PLA/PHA blend leads to a significant reduction in deformation during aging [12]. A higher degree of crystallinity of the PLA/PHA cosmetic container may increase the stability of the material at elevated temperature [40]. For further research, only paraffin was chosen which does not evaporate so quickly.

The changes in the thermal properties after 37 days (real-time aging of one year) of preliminary accelerated aging test of PLA cosmetic containers and after 185 days (real-time aging of five years) of accelerated aging test of both PLA and PLA/PHA cosmetic containers were examined using DSC analysis (Table 3).

Melting enthalpies increase during aging of the PLA cosmetic containers filled with cosmetic simulants occurred in the following order: jar with ethanol $>$ jar with paraffin $>$ jar with water, indicating that the aging with cosmetic simulants causes an increase in the crystalline phase of the jars. The largest increase was noted for aging with ethanol, $\Delta H_{m}=33.07 \mathrm{~J} / \mathrm{g}$ (before aging $\Delta H_{m}=$ $2.45 \mathrm{~J} / \mathrm{g}$ ) together with a slight decrease in $T_{g}$, which indicates the highest increase in the crystalline phase of this material and thus the highest degradation, which is also confirmed by the GPC analysis (see Figure 3). Also, for this material there is no cold crystallization effect. A cold crystallization exotherm can be detected at temperatures between $T_{g}$ and $T_{m}$ and commonly occurs in the DSC trace of amorphous to partially crystallized semicrystalline polymers when the polymers are heated to a temperature above $T_{g}$, at which the crystallizable polymer chains possess enough segmental mobility to crystallize. The crystallinity of PLA and PLA/PHA samples after 185 days of degradation with paraffin, and blank test increased after a long time due to the degradation process. The cold crystallization enthalpy of samples aging after 37 days in the paraffin, water and blank test almost did not differ from the consecutive melting enthalpies, confirming that the PLA cosmetic containers were amorphous. The cold crystallization phenomenon was observed during the heating run at $5{ }^{\circ} \mathrm{C} / \mathrm{min}$ for all amorphous samples received previously after rapid cooling from $200{ }^{\circ} \mathrm{C}$. 
Table 3. Calorimetric parameters of PLA cosmetic containers filled with paraffin (P) ethanol (E), deionized water (H), and blank test (BT) before degradation (jar bottom), and after 37 days of the accelerated aging test as well as PLA/PHA cosmetic containers filled with paraffin (P), and blank test (BT) before degradation (jar bottom), and after 185 days of the accelerated aging. First calorimetric trace was acquired at $20^{\circ} \mathrm{C}$ as well as second and third calorimetric traces (after rapid cooling from $200{ }^{\circ} \mathrm{C}$ ) at $20^{\circ} \mathrm{C} / \mathrm{min}$ and $5{ }^{\circ} \mathrm{C} / \mathrm{min}$, respectively).

\begin{tabular}{|c|c|c|c|c|c|c|c|c|c|c|}
\hline Variable & PLA Jar Bottom & PLA-37P & PLA-37E & $\begin{array}{l}\text { PLA-37H } \\
\end{array}$ & PLA-37BT & PLA-185P & PLA-185BT & PLA/PHA Jar Bottom & PLA/PHA-185P & PLA/PHA-185BT \\
\hline \multicolumn{11}{|c|}{ I-calorimetric trace, $20^{\circ} \mathrm{C} / \mathrm{min}$} \\
\hline$T_{m}\left({ }^{\circ} \mathrm{C}\right)$ & 151.2 & 155.2/169.2/175.4 & $142.2 / 149.1 / 152.5 / 157.5$ & 152.4 & 151.5 & $127.9 / 152.1$ & $127.3 / 152.8$ & 151.8/171.1 & $153.8 / 170.0$ & $154.3 / 170.2$ \\
\hline$\Delta H_{m}(\mathrm{~J} / \mathrm{g})$ & 2.45 & 5.47 & 33.07 & 3.87 & 2.90 & $1.47 / 23.22$ & $1.74 / 23.77$ & 21.0 & 28.9 & 30.1 \\
\hline$T_{c c}\left({ }^{\circ} \mathrm{C}\right)$ & 129.3 & 116.4 & - & 127.8 & 121.2 & - & - & 114.1 & - & - \\
\hline$\Delta H_{c c}(\mathrm{~J} / \mathrm{g})$ & -2.92 & -5.03 & - & -3.76 & -2.95 & - & - & -20.55 & - & - \\
\hline \multicolumn{11}{|c|}{ II-calorimetric trace after rapid cooling, $20^{\circ} \mathrm{C} / \mathrm{min}$} \\
\hline$T_{g}\left({ }^{\circ} \mathrm{C}\right)$ & 61.1 & 61.5 & 58.0 & 62.0 & 61.9 & 60.4 & 62.2 & $2.0 / 59.7$ & $1.3 / 57.7$ & $1.0 / 57.0$ \\
\hline$\Delta c p\left(\mathrm{~J} / \mathrm{g}^{\circ} \mathrm{C}\right)$ & 0.52 & 0.49 & 0.50 & 0.49 & 0.49 & 0.52 & 0.48 & $0.06 / 0.46$ & $0.04 / 0.47$ & $0.04 / 0.47$ \\
\hline$T_{m}\left({ }^{\circ} \mathrm{C}\right)$ & 149.6 & 149.4 & 152.1 & - & - & 150.9 & - & $154.1 / 173.6$ & $153.3 / 170.3$ & 154.1/170.1 \\
\hline$\Delta H_{m}(\mathrm{~J} / \mathrm{g})$ & 0.38 & 0.19 & 0.44 & - & - & 0.37 & - & 0.65 & 0.79 & 4.19 \\
\hline$T_{c c}\left({ }^{\circ} \mathrm{C}\right)$ & 138.2 & & 139.1 & - & - & 139.1 & - & 142.5 & 139.0 & 135.1 \\
\hline \multicolumn{11}{|c|}{ III-calorimetric trace after rapid cooling, $5^{\circ} \mathrm{C} / \mathrm{min}$} \\
\hline$T_{g}\left({ }^{\circ} \mathrm{C}\right)$ & 58.7 & 58.4 & 55.7 & 58.0 & 58.2 & 57.6 & 58.1 & $-0.9 / 56.1$ & $-0.2 / 54.9$ & $-0.1 / 54.8$ \\
\hline$\Delta c p\left(\mathrm{~J} / \mathrm{g}^{\circ} \mathrm{C}\right)$ & 0.56 & 0.49 & 0.54 & 0.47 & 0.48 & 0.54 & 0.5 & $0.05 / 0.50 /$ & $0.04 / 0.48$ & $0.04 / 0.47$ \\
\hline$T_{m}\left({ }^{\circ} \mathrm{C}\right)$ & 150.0 & 150.0 & $148.8 / 153.1$ & 151.0 & 150.8 & 150.7 & 151.6 & $150.4 / 172.1$ & $149.8 / 154.2 / 171.5$ & $150.0 / 154.4 / 172.0$ \\
\hline$\Delta H_{m}(\mathrm{~J} / \mathrm{g})$ & 10.21 & 6.26 & 26.28 & 9.63 & 7.51 & 18.25 & 12.21 & $20.50 / 5.25$ & $22.76 / 5.47$ & 33.64 \\
\hline$T_{c c}\left({ }^{\circ} \mathrm{C}\right)$ & 123.5 & 125.8 & 118.1 & 125.9 & 126.2 & 122.3 & 126.2 & 118.7 & 116.4 & 113.5 \\
\hline$\Delta H_{c c}(\mathrm{~J} / \mathrm{g})$ & -10.21 & -6.20 & -25.93 & -9.40 & -7.50 & -18.21 & -12.03 & -24.81 & -28.14 & -33.33 \\
\hline
\end{tabular}

$T_{\text {- }}$ the cold crystallization temperature; $\Delta H_{c c}$-cold crystallization enthalpy. 
During the first heating run, for PLA cosmetic containers aging with ethanol and paraffin were noted the multiple melting endotherms. The multiple melting endotherm in the DSC curves has been reported for many semicrystalline polymers crystallized isothermally from the melt at a selective crystallization temperature. There is no single explanation for this effect. In our case it may be a consequence of (i) melting, recrystallization, and remelting during the DSC heating process; (ii) changes in the morphology (such as lamellar thickness, distribution, crystal perfection or stability); (iii) physical aging or/and relaxation of the rigid amorphous fraction; (iv) different molar mass of individual polymer chains as a result of the degradation mechanism that can lead to the formation of a multiple population of crystallites, but only in the case of aging with ethanol, where a relatively high degree of degradation was observed (see Figure 3) [6,41]. In the case of PLA samples after 185 days of degradation with paraffin, and blank test, the double melting endotherm indicates most likely different molar mass of individual polymer chains resulting from the degradation mechanism. During the second heating run after a rapid cooling, for aging with deionized water, and for blank test for both aging times (37 and 185 days) the PLA samples had no chance of nucleation during cooling and thus only showed $T_{g}$. Samples analyzed at $20^{\circ} \mathrm{C} / \mathrm{min}$ do not crystallize likely due to low degradation degree. Heating rate of $5{ }^{\circ} \mathrm{C} / \mathrm{min}$ allows the crystallization of all materials. During the second heating run at $20^{\circ} \mathrm{C} / \mathrm{min}$, for aging PLA with ethanol after 37 days and with paraffin after 185 days as well as for aging of PLA/PHA samples after 185 days, except for the blank test, the crystallization and melting effects are low, which indicates slow nucleation and crystallization.

The molar mass loss of cosmetic containers during aging using cosmetic simulant paraffin and blank test occurred in the following order: PLA with paraffin > PLA/PHA blank test > PLA blank test $>$ PLA/PHA with paraffin, respectively (Figure 2).
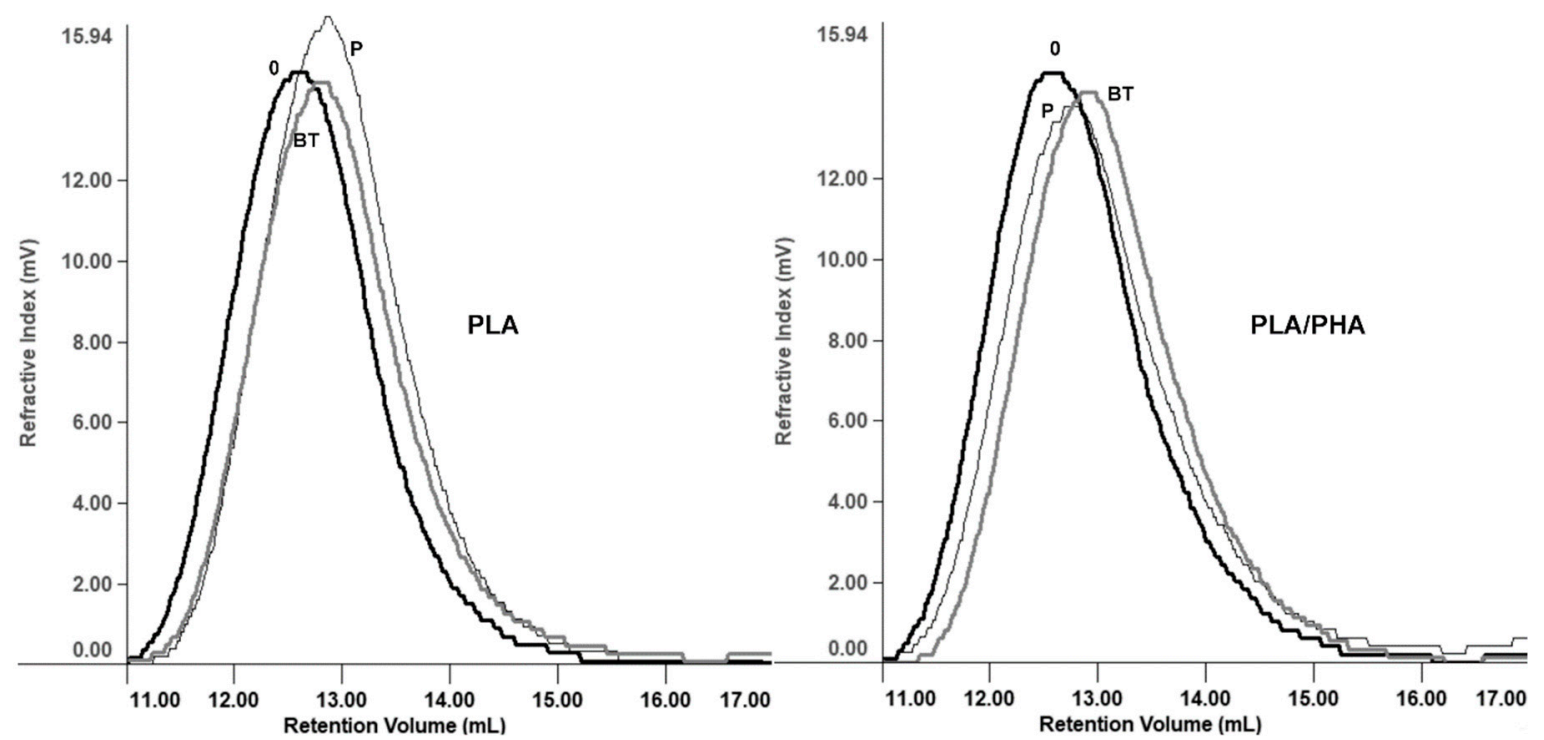

Figure 2. Overlay of selected GPC elugrams of PLA and PLA/PHA cosmetic containers filled with paraffin (P), and blank test (BT) before aging (0) and after 185 days (real-time aging of five years) of the accelerated aging test at $55^{\circ} \mathrm{C}$.

We originally demonstrated, that degradation of PLA film samples occurs in paraffin due a residual water content $[3,6]$. The same effect causes a faster degradation of the PLA cosmetic containers filled with paraffin (Figure 3). The residual content of water can be absorbed from hydrophobic paraffin and the environment by the dry PLA container and penetrate into polymer matrix, generating an autocatalytic effect. Faster internal degradation of polylactide is regarded as a general phenomenon [3,42]. Paraffin also has a heat buffering capacity and it has also been proven that it has a cooling effect $[43,44]$, which is why it slowed the degradation of the temperature-sensitive PHA in the blend and thus the degradation of entire container. 


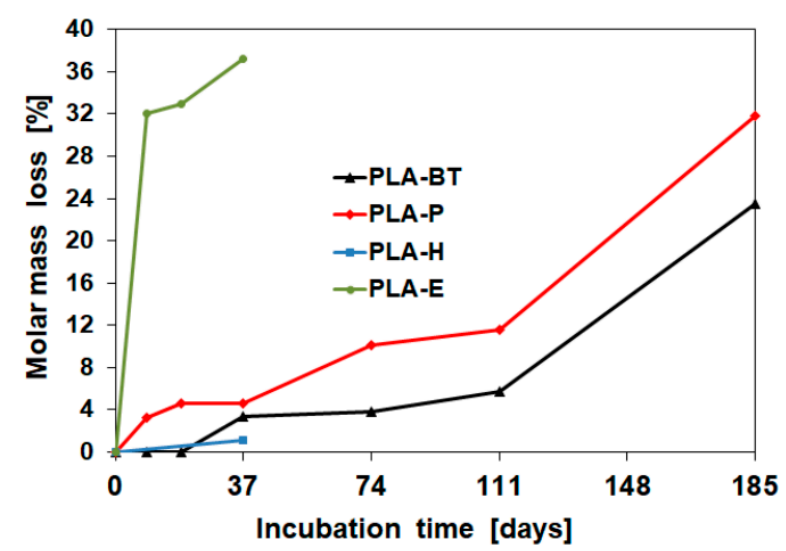

Figure 3. Molar mass loss of PLA cosmetic containers filled with paraffin (P), ethanol (E), deionized water $(\mathrm{H})$, and blank test $(\mathrm{BT})$ as a function of incubation time of the accelerated aging test at $55{ }^{\circ} \mathrm{C}$. The molar mass loss is given as a percentage of the original mass-average molar mass.

Hydrolysis and alcoholysis may share the same mechanism, but differ in acyl acceptors (water or ethanol) and may occur without catalysts. The highest degree of degradation occurred in the case of ethanol. For deionized water, this degree was small, due to the largest deformation of the jar and evaporation of water during degradation. Performed studies for both materials-PLA and PLA/PHA blend - have shown that degradation of those material accelerates after 111 days of aging with paraffin, and for blank test (real-time aging of three years), which is advantageous from the viewpoint of products with a long shelf-life application of three years.

\subsection{D-Printed Container/Cosmetic Formulation Compatibility Test}

The compatibility tests were based on determining the interaction of the cosmetic formulation with the packaging in the surrounding environment in order to verify their fit. The packaging should be compatible with the product, which means that all ingredients of the cosmetic formulation do not affect the packaging and vice versa, the packaging components do not react with the cosmetic formulation. The basis for the selection of the correct packaging is knowledge about the ingredients of the recipe. The evaluation criteria taken into account for both packaging and cosmetic formulation are appearance, color and odor [45].

After 12 weeks of compatibility test for PLA cosmetic containers, similar relationships were observed for all samples. The jars were highly swollen, and the cosmetic formulations leaked or evaporated, so that the tests were negative. In the case of PLA/PHA cosmetic containers in the middle of the compatibility test (after 6 weeks) the first changes, such as a slight opening of the jars and a small mass loss (vaporization of $10 \%$ for ambient temperature and from $15 \%$ to $20 \%$ for $45^{\circ} \mathrm{C}$ ) only for more moisturizing cosmetic formulations with no changes in color or odor as well as with no deformations or swelling of the jars could be noted (Table 4). After 12 weeks at ambient temperature, regardless of the type of cosmetic formulation, the jars have opened more with a mass loss of $50-70 \%$ for more moisturizing and $30-40 \%$ for oily cosmetic formulations. For the cosmetic containers with cosmetic formulations incubated at $45^{\circ} \mathrm{C}$, a significant mass loss of $75-80 \%$ for more moisturizing and $60-75 \%$ for oily cosmetic formulations were noticed with a slight change in color (darkening) as well as an odor (unpleasant, pungent) in one oily formulation and significant vaporization for one moisturizing formulation (Table 4). Odor change did not occur during tests in conventional polypropylene cosmetic containers, although the change in color to darker depends mainly on temperature (own research by Dr. Irena Eris Cosmetic Laboratories). During the compatibility test, the deformation of cosmetic containers was in the range of $1-5 \%$. No cracks occurred, and the color of the jars did not change. 
Table 4. Compatibility test of PLA/PHA cosmetic containers with cosmetic formulations from the moisturizing to oily performed at ambient temperature and at $45^{\circ} \mathrm{C}$ during 6 and 12 weeks.

\begin{tabular}{|c|c|c|c|c|c|c|c|c|c|c|c|}
\hline \multirow{3}{*}{$\begin{array}{c}\text { Cosmetic } \\
\text { Formulation }\end{array}$} & \multirow{3}{*}{$\begin{array}{l}\text { Viscosity } \\
\text { (mPa.s) }\end{array}$} & \multirow{3}{*}{$\begin{array}{l}\text { Density } \\
\text { (g/mL) }\end{array}$} & \multirow{3}{*}{$\mathrm{pH}$} & \multicolumn{4}{|c|}{ Mass Loss (\%) } & \multicolumn{2}{|c|}{ Appearance Changes } & \multicolumn{2}{|c|}{ Odor Changes } \\
\hline & & & & \multicolumn{2}{|c|}{6 weeks } & \multicolumn{2}{|c|}{12 weeks } & 6 weeks & 12 weeks & 6 weeks & 12 weeks \\
\hline & & & & AT & $45^{\circ} \mathrm{C}$ & AT & $45^{\circ} \mathrm{C}$ & \multicolumn{2}{|c|}{$45^{\circ} \mathrm{C}$} & \multicolumn{2}{|c|}{$45^{\circ} \mathrm{C}$} \\
\hline 1 & $2300-3000$ & $0.98-1.01$ & $5.5-6.5$ & 10 & 20 & 70 & 80 & $\mathrm{NC}$ & $\mathrm{CC}$ & NC & $\mathrm{MC}$ \\
\hline 2 & $2400-3500$ & $0.98-1.02$ & $5.0-6.0$ & 10 & 15 & 50 & 75 & $\mathrm{NC}$ & $\mathrm{CC}$ & NC & MC \\
\hline 3 & $2400-4400$ & $0.97-0.99$ & $6.0-7.0$ & 10 & 20 & 60 & 80 & $\mathrm{NC}$ & $\mathrm{CC}$ & NC & MC \\
\hline 4 & $3000-5000$ & $0.98-1.00$ & $6.0-6.9$ & NC & NC & 40 & 60 & NC & $\mathrm{CC}$ & NC & SC \\
\hline 5 & $3800-4500$ & $0.98-1.10$ & $5.5-6.5$ & $\mathrm{NC}$ & NC & 30 & 75 & $\mathrm{NC}$ & $\mathrm{CC}$ & NC & MC \\
\hline
\end{tabular}

AT—ambient temperature; NC—no changes; CC—colour change; MC—minor change; SC—substantial change.

The packaging/cosmetic formulation compatibility test carried out was negative for PLA and positive for PLA/PHA cosmetic containers, which proved that the blend with the addition of PHA component has better compatibility with real cosmetic formulations.

\subsection{Cosmetic Contamination Simulation-Effect on the Course of (Bio)degradation}

In order to investigate the impact of cosmetic contamination on the course of degradation under laboratory composting conditions and under natural weathering conditions, a comparative degradation test of empty cosmetic containers (blank test) and cosmetic containers with a small amount of paraffin were carried out.

Ultimate biodegradation is the decomposition of organic compounds caused by microorganisms, in aerobic conditions to $\mathrm{CO}_{2}$, water and mineral salts (mineralization) and new biomass, while in anaerobic conditions to $\mathrm{CO}_{2}$, methane $\left(\mathrm{CH}_{4}\right)$, mineral salts and new biomass. In order to confirm the biodegradability of packaging materials and their ability to disintegrate under the influence of enzymes produced by bacteria and fungi, preliminary biodegradation tests were carried out under simulated composting conditions, in accordance with the method specified in PN-EN 14806: 2010 [46] and US ASTM standard D 6400 [35]. This method simulates ambient conditions found in industrial composting plants. The biodegradation tests were performed under laboratory conditions simulating aerobic composting. The $\mathrm{CO}_{2}$ released during biodegradation of the samples was measured in accordance with the test procedure at constant process parameters. The calculated degree of biodegradation and mass loss of PLA and PLA/PHA cosmetic containers during aerobic laboratory composting are presented in Table 5.

Table 5. Biodegradation results after 84 days of laboratory composting.

\begin{tabular}{ccc}
\hline Sample & The Degree of Biodegradation (\%) & Mass Loss (\%) \\
\hline PLA empty jar (blank test) & 21 & 5 \\
PLA jar with paraffin (cosmetic & 34 & 10 \\
contamination simulation) & 30 & 6 \\
PLA/PHA empty jar (blank test) & 32 & 10 \\
PLA/PHA jar with paraffin (cosmetic & & \\
\hline
\end{tabular}

The degree of biodegradation of cosmetic containers during laboratory composting occurred in the following order: PLA jar with paraffin > PLA/PHA jar with paraffin > PLA/PHA empty jar > PLA empty jar, respectively. The degradation of polyesters during organic recycling in biological environments, including anaerobic and aerobic conditions, results from enzymatic attack or simple hydrolysis or both [47]. PLA is widely considered as a biodegradable polymer, however, poly $(\alpha$-hydroxy acid)-type polyesters are being proven to degrade in the compost rather as a result of simple chemical hydrolysis occurring relatively quickly in these conditions, despite the fact that some fungi strains, such as Penicillium verrucosum and Aspergillus ustus can cleave their main chain $[7,48]$. Therefore, the degradation of empty PLA cosmetic containers during laboratory composting was slower than for those with the addition of PHA. The presence of microbial-derived PHA accelerates the 
degradation process. The degree of biodegradation of PLA and PLA/PHA cosmetic containers during laboratory composting after 84 days was higher for cosmetic containers with paraffin simulating cosmetic contamination.

The changes in the thermal properties after 84 days of laboratory composting and after 128 and 365 days of the natural weathering conditions of PLA and PLA/PHA cosmetic containers were examined using DSC analysis (Table 6).

The melting enthalpies increase together with a decrease in $T_{g}$ and $T_{m}$ during laboratory composting of the cosmetic containers especially for samples filled with paraffin, indicating that the paraffin induce (bio)degradation and an increase in the crystalline phase of the jars. Only PLA cosmetic container filled with paraffin exhibited a cold crystallization effect during the first heating run at $20^{\circ} \mathrm{C} / \mathrm{min}$. It may be a plasticization effect (by degradation products) that reduces $T_{g}$ and $T_{m}$ and allows crystallization in the first heating run. Other samples analyzed at $20^{\circ} \mathrm{C} / \mathrm{min}$ do not crystallize. Heating rate of $5{ }^{\circ} \mathrm{C} / \mathrm{min}$ allows the crystallization of all materials. During the second heating run at $20^{\circ} \mathrm{C} / \mathrm{min}$, all the examined samples (amorphous samples previously obtained by rapid cooling from $200^{\circ} \mathrm{C}$ ) exhibited a cold crystallization effect. However, for PLA cosmetic container (bio)degradation, crystallization and melting effects are low, which indicates slow nucleation and crystallization and therefore slow (bio)degradation. It is well known that the $T_{g}$ of a polymer depends on the length of the chain. It can be observed that, for the PLA cosmetic container filled with paraffin a significant decrease in $T_{g}$, of approximately $52 \%$, accompanied a further decrease in mass-average molar mass $M_{w}$ up to $7000 \mathrm{~g} / \mathrm{mol}$ ( $96 \%$ of molar mass loss, see Figure 4). The same effect was noticed for other samples with comparable amount of biodegradation degree: PLA/PHA empty jar and PLA/PHA jar filled with paraffin. In the first heating run for a PLA cosmetic container filled with paraffin a multiple melting endotherm was noted. This effect did not occur in the second heating run due to different sample thermal history.

In contrast to the degradation under laboratory composting conditions, samples degraded under natural weathering conditions have not been noted any significant changes in the thermal properties. Only in the case of cosmetic containers from the PLA/PHA blend, a slight increase in melting enthalpies value was observed along with a slight decrease in $T_{g}$ and $T_{m}$. During the second heating run after a rapid cooling, for cosmetic containers from the PLA and PLA filled with paraffin the samples had no chance of nucleation during cooling and thus only showed $T_{g}$. Samples analyzed at $20{ }^{\circ} \mathrm{C} / \mathrm{min}$ do not crystallize. Heating rate of $5{ }^{\circ} \mathrm{C} / \mathrm{min}$ allows the crystallization of those samples, just like for the other materials. For cosmetic containers from the PLA/PHA blend, with and without paraffin in the second heating run, crystallization and melting are low, which indicates slow nucleation, and crystallization.

Both, under composting conditions (laboratory compost, composting pile and BIODEGMA system), and under natural weathering conditions, the effect of paraffin contamination on the rate of degradation was observed (Table 6, Figures 4 and 5). Under the influence of an environment rich in enzymes produced by bacteria and fungi, paraffin accelerated the (bio)degradation as an additional carbon nutrient and energy source, while where it was the influence of natural weathering condition, in which temperature and humidity had a major role, slowed down. The molar mass loss of cosmetic containers during laboratory composting occurred in the following order: PLA jar with paraffin contamination $>$ PLA/PHA jar with paraffin contamination $>$ PLA/PHA empty jar (blank test) $>$ PLA empty jar (blank test), respectively (Figure 4A), what correlated with biodegradation degree ordering. While the order under natural weathering conditions was PLA/PHA empty jar (blank test) > PLA empty jar (blank test) $>$ jars with paraffin contamination, however, these changes are diminutive (data not shown). 
Table 6. Calorimetric parameters of PLA and PLA/PHA cosmetic containers filled with paraffin (P), and blank test (BT) before degradation (jar bottom), after 84 days of the laboratory composting and after 128 and 365 days of the natural weathering conditions. First calorimetric trace was acquired at $20{ }^{\circ} \mathrm{C}$ as well as second and third calorimetric traces (after rapid cooling from $200{ }^{\circ} \mathrm{C}$ ) at $20^{\circ} \mathrm{C} / \mathrm{min}$ and $5{ }^{\circ} \mathrm{C} / \mathrm{min}$, respectively).

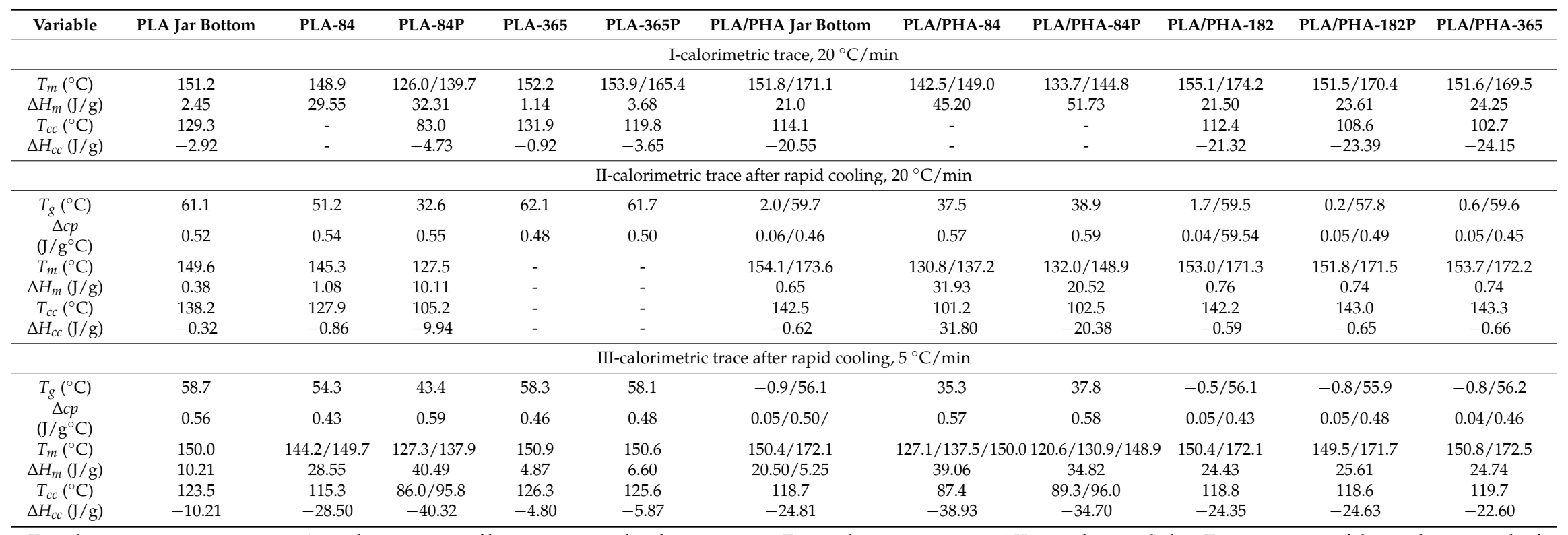

$T_{g}$-glass transition temperature, $\Delta c p$-the increment of heat capacity at the glass transition, $T_{m}$-melting temperature, $\Delta H_{m}$-melting enthalpy, $T_{c c}-$ maximum of the exothermic peak of the cold crystallization temperature, $\Delta H_{c c} \smile$ cold crystallization enthalpy. 


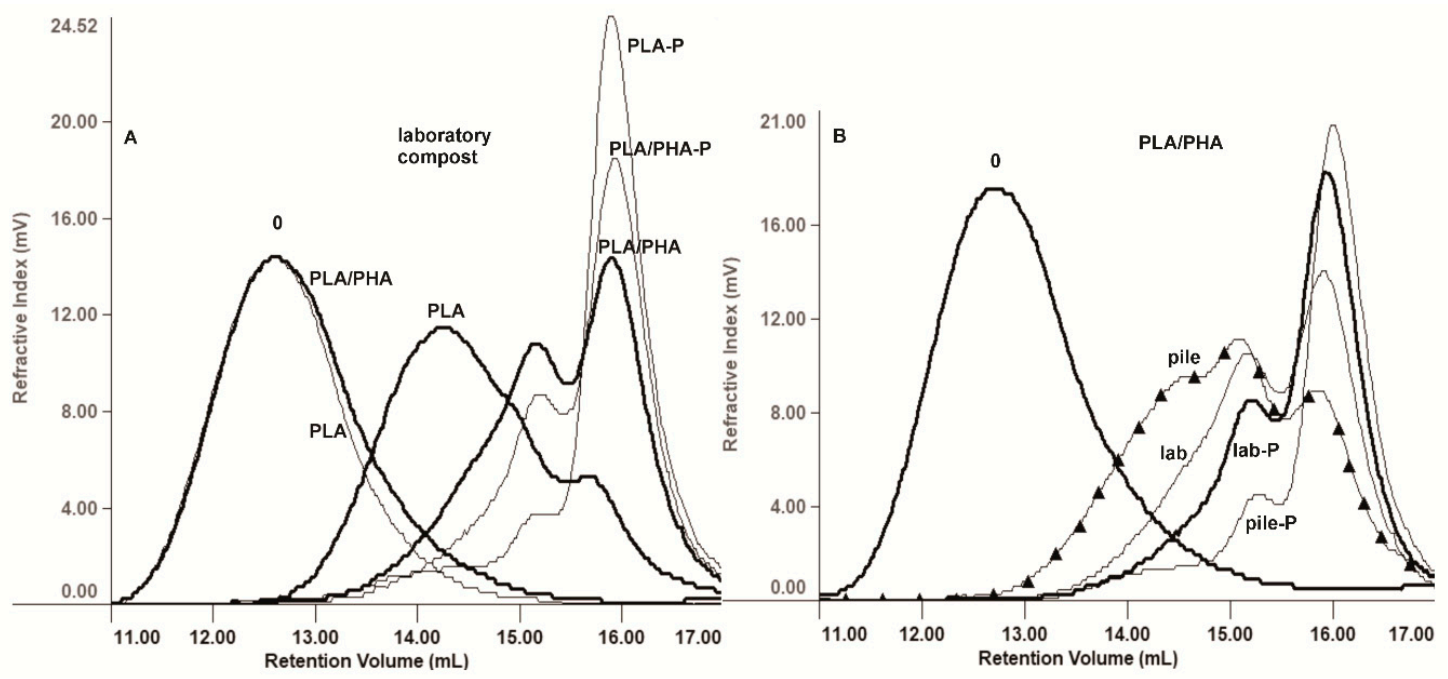

Figure 4. Overlay of selected GPC elugrams of (A): PLA and PLA/PHA cosmetic containers before degradation (0) and after 84 days of degradation in the laboratory compost and (B): PLA/PHA cosmetic containers before degradation ( 0 ) and after 84 days of degradation in the laboratory compost (lab) and in the composting pile (pile); $\mathrm{P}$-container with paraffin contamination.

The degradation progress, comparing the composting environments, after 21 days for both cosmetic containers (with paraffin and empty) was faster in the BIODEGMA system than in the composting pile (data not shown). Whereas, after 84 days the degradation of cosmetic containers with paraffin contamination was at the same level independently from environment: composting pile or laboratory compost. Then, for empty containers, the degradation for PLA/PHA occurred in the order: laboratory compost and composting pile (Figure 4B) and vice versa for PLA, because more humid environments promotes faster hydrolytic degradation of PLA material. In general, degradation in the humid compost environments was in favor of PLA containers (data not shown).

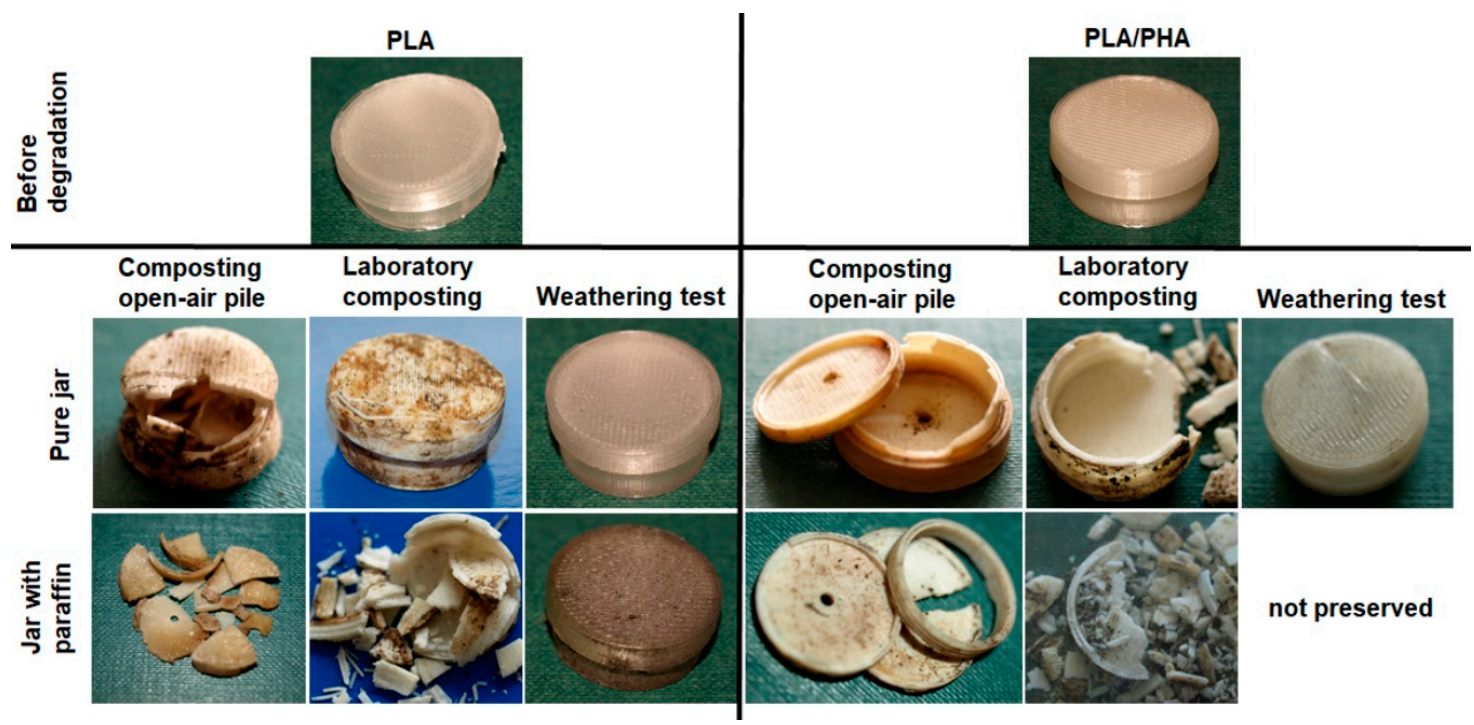

Figure 5. Photomacrographs of PLA cosmetic containers before degradation and after 84 days of the composting under laboratory and industrial conditions as well as after 365 days under natural weathering conditions.

Macroscopic visual evaluation of the PLA and PLA/PHA cosmetic containers after degradation under laboratory and industrial composting conditions showed erosion through the breaking of the specimens, especially at the point of contact of the wall with the bottom of the jar, where cohesion 
between two adjacent printed layers was weaker. However, this effect was more visible for containers incubated in industrial composting pile (Figure 5). Parts with the largest structural ordering of the material as the jar bottom and lid degrade slower compare with jar wall. For cosmetic containers with the addition of paraffin disintegration occurs much faster because paraffin contamination accelerates the degradation. Material containing PHA is usually less transparent (yellowish) than PLA itself, however, during degradation of the PLA-based material, a decrease in transparency and milky-white color was observed due to increased crystallinity [3,12].

Both the ex-ante investigations as well as the ex-post studies are needed in the area of advanced polymer material applications (especially of long-shelf life products such as cosmetics or household chemicals) in order to increase efficiency and to define and minimize the potential failure of novel (bio)degradable polymer products before and after specific use. Comprehensive predictive studies may help to design novel polymeric materials and to avoid the failures of existing ones. The modeling and simulations of degradation using the tests performed allow predicting the behavior of advanced materials during their use and disposal. Knowledge of degradation and damage phenomena of (bio)degradable polymer materials in service conditions and thus the prediction of behavior under operating conditions, indicates the scope and capabilities as well as limitations of using these polymers as advanced polymeric materials. The evaluation protocol summarizing the work is presented in Table 7 .

Table 7. Testing of long-term (bio)degradable polymers.

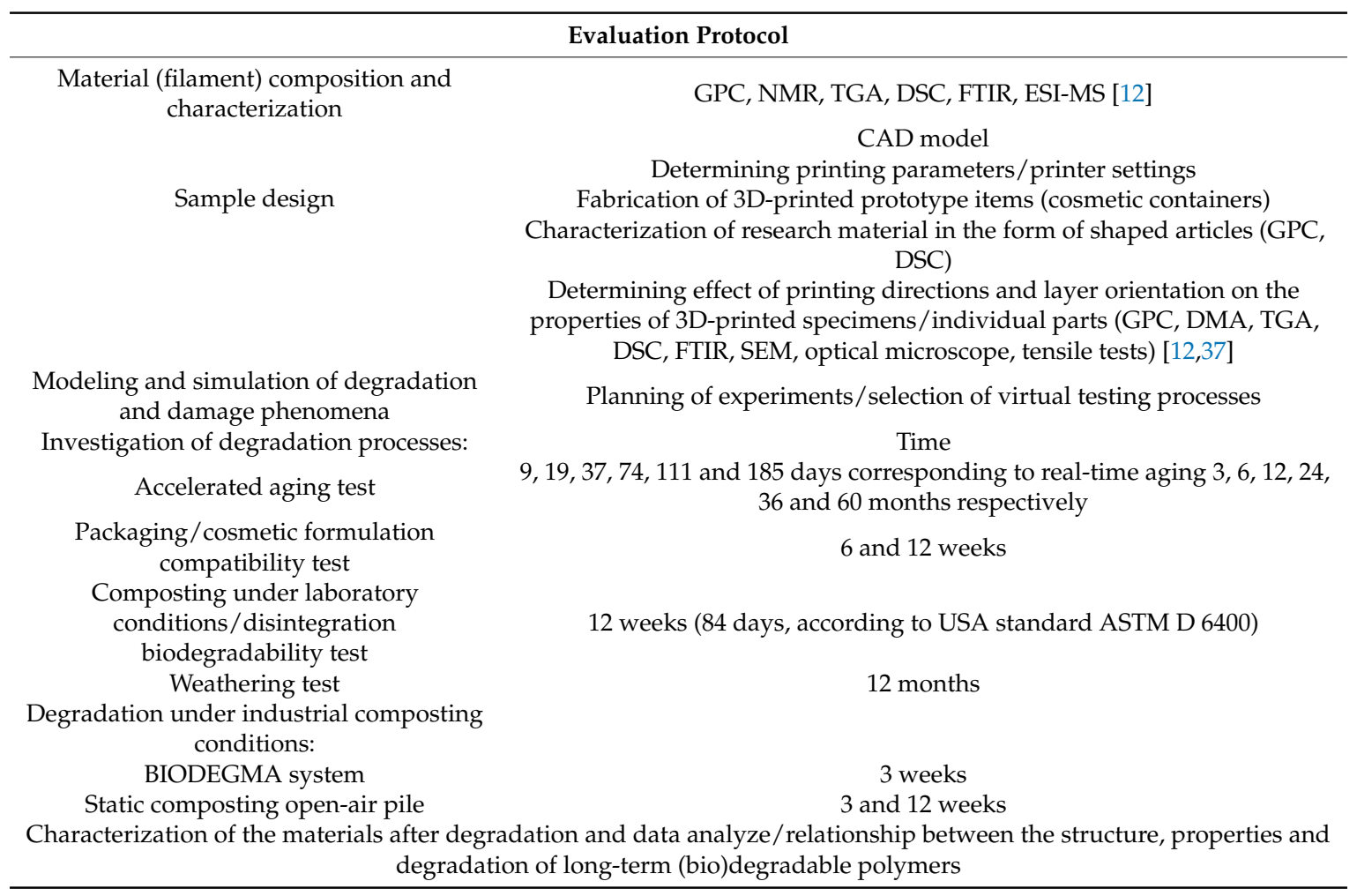

\section{Conclusions}

Based on the knowledge of the cosmetic formulation and packaging material, as well as on the basis of available standards for the packaging of medical, pharmaceutical, and food products, a comprehensive strategy of standard procedure for cosmetic products was developed to characterize the degradation pathways of polymeric systems (PLA and PLA/PHA containers made with 3D printing). These procedures involved virtual tests under different environmental conditions, including accelerated aging test, packaging/cosmetic formulation compatibility test with real cosmetic formulations, composting under laboratory, and industrial conditions as well as weathering test. 
The performed study of modeling and simulation of degradation and damage phenomena have shown that: (i) microbial-based PHA component during accelerated aging test at $55^{\circ} \mathrm{C}$ and during incubation in environments rich in microorganisms accelerated the degradation process of material investigated; (ii) paraffin accelerates PLA degradation due to the residual water content and slows down PHA-based material degradation because of paraffin heat buffering capacity and a cooling effect; (iii) under the influence of an environment rich in enzymes produced by bacteria and fungi, paraffin contamination accelerates the biodegradation; (iv) under the influence of natural weathering condition paraffin contamination slowed down degradation due to its hydrophobicity and water-repellent activity; (v) aging PLA and PLA/PHA container with paraffin, accelerated after 111 days corresponding to real time-three years, which is advantageous from the viewpoint of products with a long shelf-life applications. The processing conditions, in particular the printing orientation of individual parts of the container, influenced the material properties at its various regions, affecting the rate of degradation of individual parts and the simulated shelf life. Accelerated aging tests of prototype packages using cosmetic simulants have shown that cosmetic containers have been deformed from the beginning of experiments especially in the case of PLA material, so for PLA cosmetic containers the tests were negative. For PLA/PHA cosmetic containers, it has been proved that the material (in this case a blend) with the addition of more hydrophobic PHA component demonstrated better compatibility with the cosmetic formulations. The selection of test procedures allow to indicate limitations both in the preparation of the finished product package and its shelf life.

Author Contributions: Conceptualization, J.R. and M.K.; Methodology, J.R. and M.M.-M.; Formal analysis, W.S., M.M., and H.J.; Investigation, J.R., W.S., M.M., and J.Ł.; Resources, J.R., J.W., and M.K.; Writing-original draft preparation, J.R.; Writing—review and editing, J.R., W.S., M.M., H.J., and M.K.; Visualization, J.R.; Supervision, J.R.; J.R. contributed $58 \%$ while the other authors contributed within $42 \%$ equally. All authors have given approval to the final version of the manuscript.

Funding: This work was partially supported by the European Regional Development Fund Project EnTRESS No 01R16P00718.

Acknowledgments: This work was supported by the National Scholarship Programme of the Slovak Republic for the support of mobility of students, PhD students, university teachers, researchers, and artists.

Conflicts of Interest: The authors declare no conflict of interest.

\section{References}

1. Kharina, A. EU Regulation: Packaging is a New "Cosmetic Ingredient". 2016. Available online: https: / / knowledge.ulprospector.com/5688/pcc-eu-regulation-packaging-new-cosmetic-ingredient/ (accessed on 3 December 2018).

2. Rydz, J.; Wolna-Stypka, K.; Adamus, G.; Janeczek, H.; Musioł, M.; Sobota, M.; Marcinkowski, A.; Krzan, A.; Kowalczuk, M. Forensic engineering of advanced polymeric materials. Part 1-degradation studies of polylactide blends with atactic poly[(R,S)-3-hydroxybutyrate] in paraffin. Chem. Biochem. Eng. Q. 2015, 29, 247-259. [CrossRef]

3. Rydz, J.; Adamus, G.; Wolna-Stypka, K.; Marcinkowski, A.; Misiurska-Marczak, M.; Kowalczuk, M.M. Degradation of polylactide in paraffin and selected protic media. Polym. Degrad. Stab. 2013, 98, 316-324. [CrossRef]

4. Hopewell, J.; Dvorak, R.; Kosior, E. Plastics recycling: Challenges and opportunities. Philos. Trans. R. Soc. Lond. B Biol. Sci. 2009, 364, 2115-2126. [CrossRef] [PubMed]

5. Niaounakis, M. Biopolymers: Applications and Trends; Elsevier: Oxford, UK, 2015.

6. Rydz, J.; Wolna-Stypka, K.; Musioł, M.; Szeluga, U.; Janeczek, H.; Kowalczuk, M. Further evidence of polylactide degradation in paraffin and in selected protic media. A thermal analysis of eroded polylactide films. Polym. Degrad. Stab. 2013, 98, 1450-1457. [CrossRef]

7. Sikorska, W.; Musiol, M.; Nowak, B.; Pajak, J.; Labuzek, S.; Kowalczuk, M.; Adamus, G. Degradability of polylactide and its blend with poly[(R, S)-3-hydroxybutyrate] in industrial composting and compost extract. Int. Biodeterior. Biodegard. 2015, 101, 32-41. [CrossRef] 
8. Song, J.H.; Murphy, R.J.; Narayan, R.; Davies, G.B.H. Biodegradable and compostable alternatives to conventional plastics. Philos. Trans. R. Soc. Lond. B Biol. Sci. 2009, 364, 2127-2139. [CrossRef] [PubMed]

9. Rychter, P.; Biczak, R.; Herman, B.; Smyłła, A.; Kurcok, P.; Adamus, G.; Kowalczuk, M. Environmental degradation of polyester blends containing atactic poly(3-hydroxybutyrate). Biodegradation in soil and ecotoxicological impact. Biomacromolecules 2006, 7, 3125-3131. [CrossRef]

10. Rychter, P.; Biczak, R.; Herman, B.; Zawierucha, I.; Musioł, M.; Sobota, M.; Kowalczuk, M. Environmental degradation of aromatic-aliphatic polyester blends. Evaluation of degradation products in soil and their phytotoxicological impact. Pol. J. Environ. Stud. 2011, 20, 293-298.

11. Castro-Aguirre, E.; Auras, R.; Selke, S.; Rubino, M.; Marsh, T. Insights on the aerobic biodegradation of polymers by analysis of evolved carbon dioxide in simulated composting conditions. Polym. Degrad. Stab. 2017, 137, 251-271. [CrossRef]

12. Gonzalez Ausejo, J.; Rydz, J.; Musioł, M.; Sikorska, W.; Sobota, M.; Włodarczyk, J.; Adamus, G.; Janeczek, H.; Kwiecień, I.; Hercog, A.; et al. A comparative study of three-dimensional printing directions: The degradation and toxicological profile of a PLA/PHA blend. Polym. Degrad. Stab. 2018, 152, 191-207. [CrossRef]

13. Włodarczyk, J.; Sikorska, W.; Rydz, J.; Johnston, B.; Jiang, G.; Radecka, I.; Kowalczuk, M. 3D processing of PHA containing (bio)degradable material. In Current Advances in Biopolymer Processing Characterization Biomaterials-Properties, Production and Devices Series; Koller, M., Ed.; Nova Science Publishers: New York, NY, USA, 2018; Chapter 6; pp. 121-168.

14. Rydz, J.; Sikorska, W.; Kyulavska, M.; Christova, D. Polyester-based (bio)degradable polymers as environmentally friendly materials for sustainable development. Int. J. Mol. Sci. 2015, 16, 564-596. [CrossRef]

15. Musioł, M.; Janeczek, H.; Jurczyk, S.; Kwiecień, I.; Sobota, M.; Marcinkowski, A.; Rydz, J. (Bio) degradation studies of degradable polymer composites with jute in different environments. Fibers Polym. 2015, 16, 1362-1369. [CrossRef]

16. Musioł, M.; Rydz, J.; Janeczek, H.; Radecka, I.; Jiang, G.; Kowalczuk, M. Forensic engineering of advanced polymeric materials Part IV: Case study of oxo-degradable polyethene commercial bags-Aging in biotic and abiotic environment. Waste Manag. 2017, 64, 20-27. [CrossRef]

17. RPC Group. PHA Nowy Polimer Biodegradowalny W Opakowaniach Kosmetyków. 2006. Available online: http:/ / opakowania.com.pl/news/pha-nowy-polimer-biodegradowalny-w-opakowaniach-kosmetykow26008.html (accessed on 28 March 2018).

18. Redaktion, Leoplast Group: Green Packaging from Italy. 2010. Available online: http:/ /www.leoplastgroup. com/eng/home_vegetal.html (accessed on 28 March 2018).

19. Malik, C.J. CARGO PlantLove Botanical Lipstick. 2007. Available online: http://www.treehugger.com/ style/cargo-plantlove-botanical-lipstick.html (accessed on 28 March 2018).

20. Musioł, M.; Sikorska, W.; Adamus, G.; Janeczek, H.; Kowalczuk, M.; Rydz, J. (Bio)degradable polymers as a potential material for food packaging. Studies of PLA/(R,S)-PHB rigid foils (bio)degradation process under industrial composting conditions. Eur. Food. Res. Technol. 2016, 242, 815-823. [CrossRef]

21. Rodriguez, E.J.; Marcos, B.; Huneault, M.A. Hydrolysis of polylactide in aqueous media. J. Appl. Polym. Sci. 2016, 44152, 11. [CrossRef]

22. Musioł, M.; Sikorska, W.; Janeczek, H.; Wałach, W.; Hercog, A.; Johnston, B.; Rydz, J. (Bio)degradable polymeric materials for a sustainable future-part 1. Organic recycling of PLA/PBAT blends in the form of prototype packages with long shelf-life. Waste Manag. 2018, 77, 447-454. [CrossRef] [PubMed]

23. Sikorska, W.; Rydz, J.; Wolna-Stypka, K.; Musioł, M.; Adamus, G.; Kwiecień, I.; Janeczek, H.; Duale, K.; Kowalczuk, M. Forensic engineering of advanced polymeric materials-Part V: Prediction studies of aliphatic-aromatic copolyester and polylactide commercial blends in view of potential applications as compostable cosmetic packages. Polymers 2017, 9, 257. [CrossRef]

24. Sikorska, W.; Musioł, M.; Rydz, J.; Zięba, M.; Rychter, P.; Lewicka, K.; Šiškova, A.; Mosnácková, K.; Kowalczuk, M.; Adamus, G. Prediction studies of environment-friendly biodegradable polymeric packaging based on PLA. Influence of specimens' thickness on the hydrolytic degradation profile. Waste Manag. 2018, 78, 938-947. [CrossRef]

25. Guidelines on Stability Testing of Cosmetic Products. CTFA and Colipa. 2004. Available online: http: / / www.packagingconsultancy.com/pdf/cosmeticscolipa-testing-guidelines.pdf (accessed on 4 June 2018).

26. EN 1186. Materials and Articles in Contact with Foodstuffs_Plastics; European Committee for Standardization: Brussels, Belgium, 2002. 
27. Legislation Cosmetics (eu). Available online: https://ec.europa.eu/growth/sectors/cosmetics/legislation (accessed on 4 June 2018).

28. Regulation (EC) of the European Parliament and the Council of the European Union of 30 November 2009 on Cosmetic Products (eu) no 1223/2009. Available online: https:/ / eur-lex.europa.eu/legal-content/EN/ ALL/?uri=CELEX\%3A32009R1223 (accessed on 4 December 2018).

29. Commission Implementing Decision on Guidelines on Annex I to Regulation (EC) no 1223/2009 of 25 November 2013 on Cosmetic Products (eu) no 2013/674/EU. Available online: https: / / eur-lex.europa.eu/ legal-content/EN/TXT/?uri=CELEX\%3A32013D0674 (accessed on 4 December 2018).

30. Life Science Outsourcing, Inc. Medical Package Testing. Accelerated Aging Medical Package Testing Services. Available online: https://lso-inc.com/medical-package-testing/accelerated-aging.html (accessed on 4 June 2018).

31. Dorweiler, K.J.; Gurav, J.N.; Walbridge, J.S.; Ghatge, V.S.; Savant, R.H. Determination of Stability from Multicomponent Pesticide Mixes. J. Agric. Food Chem. 2016, 64, 6108-6124. [CrossRef] [PubMed]

32. Columbus Instruments. Available online: http:/ / www.colinst.com (accessed on 23 November 2018).

33. Testing Guideline on the Degradability and Food Safety of Containers and Bags. Part 2: Biodegradability Test, HS 2001. Hong Kong Productivity Council/Environmental Protection Department. Available online: https: / / www.wastereduction.gov.hk/sites/default/files/en/materials/info/container/Part2_cover.pdf (accessed on 4 December 2018).

34. Bajer, K.; Kaczmarek, H. Metody badania biodegradacji materiałów polimerowych (Methods for testing the biodegradation of polymeric materials). Polimery 2007, 52, 13-18. [CrossRef]

35. ASTM Standard D6400-04. Standard Specification for Compostable Plastics; ASTM International: West Conshohocken, PA, USA, 2004.

36. Musioł, M.T.; Rydz, J.; Sikorska, W.J.; Rychter, P.R.; Kowalczuk, M.M. A preliminary study of the degradation of selected commercial packaging materials in compost and aqueous environments. Pol. J. Chem. Tech. 2011, 13, 55-57. [CrossRef]

37. Gonzalez Ausejo, J.; Rydz, J.; Musioł, M.; Sikorska, W.; Janeczek, H.; Sobota, M.; Włodarczyk, J.; Szeluga, U.; Hercog, A.; Kowalczuk, M. Three-dimensional printing of PLA and PLA/PHA dumbbell-shaped specimens of crisscross and transverse patterns as promising materials in emerging application areas: Prediction study. Polym. Degrad. Stab. 2018, 156, 100-111. [CrossRef]

38. ASTM F1980-16. Standard Guide for Accelerated Aging of Sterile Barrier Systems for Medical Devices; Developed by Subcommittee F02.50 on Package Design and Development; American Society for Testing and Materials: West Conshohocken, PA, USA, 2016.

39. Liang, F.; Todd, B.L.; Saini, R.K. Reinforcing amorphous PLA with Solid Particles for Downhole Applications. European Patent EP 2764068 A1, 20 September 2012.

40. Lee, R.E.; Guo, Y.; Tamber, H.; Planeta, M.; Leung, S.N.S. Thermoforming of polylactic acid foam sheets: Crystallization. Ind. Eng. Chem. Res. 2016, 55, 560-567. [CrossRef]

41. Xu, C.; Qiu, Z. Nonisothermal melt crystallization and subsequent melting behavior of biodegradable poly(hydroxybutyrate)/multiwalled carbon nanotubes nanocomposites. J. Polym. Sci. B Polym. Phys. 2009, 47, 2238-2246. [CrossRef]

42. Siparsky, G.L.; Voorhees, K.J.; Miao, F. Hydrolysis of polylactic acid (PLA) and polycaprolactone (PCL) in aqueous acetonitrile solutions: Autocatalysis. J. Polym. Environ. 1988, 6, 31-41. [CrossRef]

43. Cao, H. Smart coatings for protective clothing. In Active Coatings for Smart Textiles; Hu, J., Ed.; Woodhead Publishing Series in Textile; Woodhead Publishing, Elsevier: Cambridge, UK, 2016; pp. 375-389. [CrossRef]

44. Bremerkamp, F.; Seehase, D.; Nowottnick, M. Heat protection coatings for high temperature electronics. In Proceedings of the 35th International Spring Seminar on Electronics Technology, Bad Aussee, Austria, 9-13 May 2012; pp. 9-14. [CrossRef]

45. Jakubowska-Stokowska, J. Rola testów kompatybilności opakowań podczas wdrażania kosmetyków. Św. Przem. Kosmet. 2012, 1, 46-48.

46. PN-EN 14806. Packaging-Preliminary Evaluation of the Disintergration of Packaging Materials under Simulated Composting Conditions in a Laboratory Scale Test; Polish Committee for Standardization: Warszawa, Poland, 2010. 
47. Sikorska, W.; Dacko, P.; Sobota, M.; Rydz, J.; Musioł, M.; Kowalczuk, M.M. Degradation study of polymers from renewable resources and their blends in industrial composting pile. Macromol. Symp. 2008, 272, 132-135. [CrossRef]

48. Szumigaj, J.; Żakowska, Z.; Klimek, L.; Rosicka-Kaczmarek, J.; Bartkowiak, A. Assessment of polylactide foil degradation as a result of filamentous fungi activity. Pol. J. Environ. Stud. 2008, 17, 335-341. 